\title{
AVALIAÇÃO DA QUALIDADE DO ABACAXI “PÉROLA” MINIMAMENTE PROCESSADO ARMAZENADO SOB ATMOSFERA MODIFICADA
}

\author{
Evaluation of quality in fresh-cut 'Pérola' pineapple stored under modified atmosphere
}

\author{
Juliana Costa Bueno Santos ${ }^{1}$, Eduardo Valério de Barros Vilas Boas ${ }^{2}$, \\ Mônica Elisabeth Torres Prado ${ }^{3}$, Ana Carla Marques Pinheiro ${ }^{4}$
}

\begin{abstract}
RESUMO
Objetivou-se com este trabalho verificar o efeito da atmosfera modificada ativa sobre a qualidade do abacaxi minimamente processado. Assim, foram avaliadas as modificações físico-químicas, sensorial e microbiológica do abacaxi ‘Pérola’ minimamente processado submetido a diferentes atmosferas modificadas passiva e ativamente (controle - atmosfera modificada passiva; $5 \% \mathrm{O}_{2}+5 \% \mathrm{CO}_{2}, 2 \% \mathrm{O}_{2}+10 \% \mathrm{CO}_{2}$ ). A atmosfera com $2 \% \mathrm{O}_{2}+10 \% \mathrm{CO}_{2}$ determinou menor perda de líquido drenado, embora tal perda tenha sido desprezível. A atmosfera modificada ativa preveniu o amaciamento do abacaxi minimamente processado, reduzindo a atividade da poligalacturonase e solubilização péctica. As variáveis pH e vitamina C não foram significativamente afetadas pela atmosfera modificada ativa. Maiores valores de sólidos solúveis totais (SST) foram encontrados nos frutos sob atmosfera $5 \% \mathrm{O}_{2}+5 \% \mathrm{CO}_{2}$ e no caso dos açúcares solúveis o tratamento com $2 \% \mathrm{O}_{2}+10 \% \mathrm{CO}_{2}$ resultou em maiores teores. De acordo com análise sensorial, os frutos sob atmosfera modificada passiva se sobressaíram com relação ao sabor, aparência e cor. A análise microbiológica detectou valores insignificantes para fungos filamentosos, leveduras e coliformes a $35^{\circ}$ e $45^{\circ} \mathrm{C}$ em todos os tratamentos. Conclui-se que o abacaxi 'Pérola' minimamente processado pode ser armazenado por 8 dias, a $5^{\circ} \mathrm{C}$, sob atmosfera modificada passiva.
\end{abstract}

TERMOS PARA INDEXAÇÃO: Ananas comosus, atmosfera modificada ativa, atmosfera modificada passiva, processamento mínimo.

\begin{abstract}
The goal of this work was to verify the effect of active modified atmosphere on the quality of fresh-cut pineapple. Physical-chemical, sensory and microbiological changes of fresh-cut 'Pérola' pineapple treated with passive (control) and active $\left(5 \% \mathrm{O}_{2}+5 \% \mathrm{CO}_{2} ; 2 \% \mathrm{O}_{2}+10 \% \mathrm{CO}_{2}\right)$ modified atmosphere were studied. The $2 \% \mathrm{O}_{2}+10 \% \mathrm{CO}_{2}$ combination promoted the lowest loss of drained liquid, although they were negligible. Active modified atmosphere prevented the softening of fresh cut pineapples, reducing the poligalacturonase activity and pectin solubilization. The $\mathrm{pH}$ and ascorbic acid were not significantly affected by active modified atmosphere. Higher values of total soluble solids (TSS) were found in the slices under $5 \% \mathrm{O}_{2}+5 \% \mathrm{CO}_{2}$, whereas $2 \% \mathrm{O}_{2}+10 \% \mathrm{CO}_{2}$ promoted higher levels of total sugars. According to sensory evaluation, slices under passive modified atmosphere had better flavor, appearance and color. The microbiological analysis detected no significant values for fungus, yeasts and coliforms at $35^{\circ} \mathrm{C}$ and $45^{\circ} \mathrm{C}$ in all treatments. Fresh cut 'Pérola' pineapple can be stored for 8 days, at $5^{\circ} \mathrm{C}$, under passive modified atmosphere.
\end{abstract}

INDEX TERMS: active modified atmosphere, Ananas comosus, minimal processing, passive modified atmosphere.

(Recebido para publicação em 23 de outubro de 2003 e aprovado em 18 de Janeiro de 2005)

\section{INTRODUÇÃO}

Frutas minimamente processadas (“fresh cut”, levemente ou parcialmente processadas) são definidas como aquelas que mantêm seu estado fresco, apesar de terem sofrido alterações físicas. Elas passam por um processo de seleção, lavagem, descascamento e corte até chegarem a um produto 100\% aproveitável que é embalado a fim de se oferecer, aos consumidores, frescor, conveniência e qualidade nutricional (IFPA, 2002).
A qualidade dos produtos minimamente processados está relacionada com a manutenção de suas características sensoriais e controle da microbiota contaminante, com manutenção da qualidade da fruta intacta (FANTUZZI, 1999; VILAS BOAS, 2002; VILAS BOAS \& KADER, 2001). Essa qualidade pode ser expressa por medidas dos indicadores de qualidade, que incluem propriedades nutricionais, microbiológicas, tecnológicas e sensoriais, como aparência, sabor, aroma e textura (MARTENS \& BAARSETH, 1987).

\footnotetext{
1. Engenheira Agrônoma, Mestre em Ciência dos Alimentos, Universidade Federal de Lavras/UFLA, Departamento de Ciência dos Alimentos/DCA Caixa Postal 3037 - 37200-000 - Lavras,MG.

2. Engenheiro Agrônomo, Dr. Ciência dos Alimentos - Professor Adjunto, Pesquisador CNPq, UFLA/DCA - evbvboas@ufla.br.

3. Engenheira Agrícola, Dr. Ciência dos Alimentos - Pesquisadora CNPq, UFLA/DCA.

4. Engenheiro Agrônomo, doutorando em Ciências dos Alimentos - UFLA/DCA
} 
A sanificação e o controle da microbiota contaminante é importante na manutenção da vida de prateleira e segurança do produto fresco (BRACKETT, 1992). Logo, a adoção das boas práticas de fabricação é fundamental para a obtenção de um produto final de qualidade.

O abacaxi é considerado um dos frutos tropicais mais importantes, cuja comercialização vem se expandindo no mercado mundial, principalmente por suas apreciáveis características de sabor, aroma e cor. No Brasil, 'Smooth Cayenne' e 'Pérola' são as cultivares mais utilizadas comercialmente. Embora poucos trabalhos sobre processamento mínimo de abacaxis tenham sido publicados, o uso da refrigeração e da modificação atmosférica tem sido reportada como fundamental para a conservação (BONNAS et al., 2003; MARRERO \& KADER, 2001; SARZI, 2002; SILVA et al., 2003).

Quando a atmosfera modificada é associada à refrigeração, há substancial redução no crescimento microbiano e mudanças químicas e fisiológicas podem ser retardadas (PIROVANI et al., 1998). O acondicionamento de produtos minimamente processados em atmosfera modificada apresenta como princípio básico, a redução da concentração de $\mathrm{O}_{2}$ e acréscimo da concentração de $\mathrm{CO}_{2}$, buscando-se a desaceleração da atividade respiratória e, com esta, a redução do metabolismo e o controle do crescimento microbiano. A cada produto corresponderá uma determinada atmosfera de acondicionamento específica e adequada ao mesmo e, dependente da temperatura e do período de estocagem (DAREZZO, 2000). O controle da temperatura e boas condições sanitárias são imprescindíveis para o sucesso da tecnologia. Assim, tratamentos fitossanitários e processos adequados de higienização devem ser aplicados nos produtos hortícolas que serão embalados sob atmosfera modificada.

Em função do potencial de crescimento do setor de frutas minimamente processadas no Brasil, bem como da carência de estudos dentro desta área, especificamente sobre abacaxi minimamente processado, o presente trabalho teve por objetivo estudar o efeito da atmosfera modificada ativa sobre a qualidade de abacaxi 'Pérola' minimamente processado.

\section{MATERIAL E MÉTODOS}

Foram utilizados frutos do abacaxizeiro (Ananas comosus L. Merr) cv. Pérola, obtidos no mercado local de Lavras, MG, com casca verde e coloração amarela na porção basal. Os frutos foram lavados e imersos em solução de hipoclorito de sódio a $200 \mathrm{ppm}$ a $5^{\circ} \mathrm{C}$, durante
15 minutos, antes de serem descascados manualmente. Em seguida, os frutos foram cortados em leques com $5 \mathrm{~mm}$ de espessura e $30 \mathrm{~mm}$ de comprimento e largura, utilizando-se um multiprocessador MASTER AT (Cardano al Campo, Va, Italy; CE/BG-Prüfzert/Geprüfte Sicherheit). Estes leques foram submetidos à sanificação por imersão em solução de hipoclorito de sódio em concentração de $100 \mathrm{ppm}$ e temperatura de $5^{\circ} \mathrm{C}$, durante 3 minutos. Realizou-se drenagem utilizando-se peneiras de plástico, para retirada do excesso de líquido acumulado nas etapas anteriores.

Feito o processamento, os frutos foram acondicionados em embalagem rígida (Fruti-pack) de polipropileno $(13,5 \mathrm{~cm} \times 10 \mathrm{~cm} \times 4 \mathrm{~cm})$ e selados com filme flexível (Fruti-pack) de polietileno + polipropileno, 0,060 mm de espessura, em seladora à vácuo (São Paulo, SP, AP340, TecMaq), fazendo uso de injeção de gases para obtenção inicial de atmosfera modificada. Os tratamentos foram dispostos seguindo um esquema fatorial $3 \times 6$, sendo constituídos pelas combinações das diferentes atmosferas modificadas: atmosfera modificada (AM) passiva ou controle; atmosferas modificadas (AM) ativas com injeção inicial das seguintes misturas prontas de gases (Conservare/White Martins): $5 \%$ de $\mathrm{O}_{2}$ $+5 \%$ de $\mathrm{CO}_{2}$ e $2 \%$ de $\mathrm{O}_{2}+10 \%$ de $\mathrm{CO}_{2}$. Os frutos foram armazenados por $0,2,4,6,8$ e 10 dias, a $5 \pm 1^{\circ} \mathrm{C}$ e UR de $85 \%$. As amostras foram analisadas em intervalos de dois dias, num total de 10 dias de armazenamento, para caracterização da qualidade físico-química, química, bioquímica e microbiológica e de 8 dias de armazenamento, para análise sensorial.

Um líquido drenado foi retirado do interior das embalagens, com auxílio de papel absorvente, previamente tarado, nos intervalos de tempo determinados, ou seja, de 2 em 2 dias, e medido em mg por $150 \mathrm{~g}$ de frutos.

A firmeza foi determinada com o auxílio de um analisador de textura modelo TA.XT2i, utilizando uma sonda de aço inoxidável de $2 \mathrm{~mm}$ de diâmetro $(\mathrm{P} / 2 \mathrm{~N})$, que mediu a força de penetração desta no fruto, numa velocidade de $5 \mathrm{~mm} / \mathrm{s}$ e numa distância máxima de penetração de $10 \mathrm{~mm}$, valores estes previamente fixados. Foi utilizada uma plataforma HDP/90 como base para o texturômetro. A firmeza dos frutos foi expressa em Newtons $(\mathrm{N})$.

A pectina solúvel foi extraída de acordo com a técnica de McCready \& McComb (1952) e determinadas espectrofotometricamente a $530 \mathrm{~nm}$, segundo técnica de BlumenKrantz \& Asboe-Hansen (1973).

A extração da pectinametilesterase (PME) e poligalacturonase (PG) foi realizada segundo a técnica de 
Buescher \& Furmanski (1978), com modificações de Vilas Boas (1995). O doseamento da PME foi feito segundo Hultin et al. (1966) e Ratner et al. (1969), com modificações de Vilas Boas (1995). Uma unidade de PME foi definida como a quantidade de enzima capaz de catalisar a desmetilação de pectina correspondente ao consumo de $1 \mathrm{nmol}$ de $\mathrm{NaOH}$ por minuto, sob as condições do ensaio. O doseamento da PG foi realizado segundo Markovic et al. (1975), com modificações de Vilas Boas (1995). A atividade enzimática foi expressa em nmol de ácido galacturônico por grama de polpa por minuto.

$\mathrm{O} \mathrm{pH}$ da polpa foi obtido por potenciometria em eletrodo de vidro, utilizando um pHmetro B474 da Micronal, segundo técnica fornecida pela AOAC (1992). Acidez total titulável foi determinada pela técnica preconizada pela AOAC (1992), e expressa em porcentagem de ácido cítrico.

Os sólidos solúveis totais foram determinados por refratometria, conforme as normas da AOAC (1992), utilizando-se refratômetro tipo ABBE. Os resultados foram expressos em ${ }^{\circ}$ Brix.

Os açúcares solúveis totais foram extraídos com álcool etílico a $80 \%$ e determinados pelo método de Antrona (DISCHE, 1962). Os resultados foram expressos em g de glucose por $100 \mathrm{~g}$ de polpa.

O teor de ácido ascórbico foi determinado pelo método colorimétrico com 2,4 dinitrofenilhidrazina, após a oxidação do ácido ascórbico a ácido dehidroascórbico, segundo Strohecker \& Henning (1967). Os resultados foram expressos em mg por $100 \mathrm{~g}$ de polpa .

A análise sensorial dos frutos foi avaliada por um grupo de 11 provadores treinados, selecionados de uma equipe de 20 julgadores. Utilizou-se escala hedônica de 9 pontos, em que: 9 = ótimo; 8 = muito bom; 7 = moderadamente bom; 6 = ligeiramente bom; 5 = indiferente; 4 = ligeiramente ruim; $3=$ moderadamente ruim; 2 = muito ruim e 1 = péssimo. Os testes de sabor foram realizados em cabines individuais, usando-se luz vermelha para mascarar a cor das amostras. Para os testes de cor e aparência foram utilizadas cabines especiais de cor branca com 4 lâmpadas fluorescentes de 40 watts. As análises sensoriais foram conduzidas por 8 dias.

As análises microbiológicas foram realizadas pela contagem total de fungos filamentosos e leveduras e a contagem de coliformes a 35 e $45^{\circ} \mathrm{C}$, sendo realizadas segundo a metodologia proposta por Vanderzant \& Splittstoesser (1962). Cinqüenta gramas de amostras eram coletadas assepticamente, durante o período de armazenamento. As amostras eram diluídas em água peptonada a 0,1\% estéril e, posteriormente, feitas as diluições seriadas para a inoculação dos diferentes meios de cultura utilizados no experimento. Para contagem de fungos filamentosos e leveduras, utilizou-se o meio Batata Dextrose Agar (BDA), acidificado com ácido tartárico a 3,5\%, que, após inoculação, foi incubado a $25^{\circ} \mathrm{C}$ por $3-5$ dias. Os coliformes a $35^{\circ} \mathrm{C}$ foram quantificados utilizando-se a técnica do número mais provável (NMP). O teste presuntivo foi realizado com a inoculação de alíquotas da amostra em quatro séries de três tubos, contendo tubos de Durhan e caldo lauril sulfato triptose (LST), sendo incubados a $35^{\circ} \mathrm{C}$ por 24 a 48 horas. Consideravam-se tubos positivos para coliformes a $35^{\circ} \mathrm{C}$ aqueles que apresentaram turvação e formação de gás. Os coliformes a $45^{\circ} \mathrm{C}$ foram quantificados utilizando-se a técnica do NMP. Alíquotas foram transferidas dos tubos positivos do teste presuntivo para tubos contendo caldo Escherichia coli (EC) com tubos de Durhan; os tubos foram incubados a $45^{\circ} \mathrm{C}$ por 24 a 48 horas. Consideravam-se tubos positivos para coliformes a $45^{\circ} \mathrm{C}$ aqueles que se apresentavam com turvação e formação de gás. Os resultados foram expressos em NMP.g ${ }^{-1}$ de polpa.

A análise estatística foi feita com auxílio do programa estatístico SISVAR, Sistema de Análise de Variância (FERREIRA, 2000). Diferenças estatísticas entre médias foram detectadas pelo Teste de Tukey, ao valor nominal de $5 \%$ de probabilidade.

$\mathrm{O}$ experimento foi conduzido em delineamento experimental inteiramente casualizado, com três repetições. A parcela experimental foi constituída por duas bandejas contendo cada uma, cerca de $150 \mathrm{~g}$ de frutos.

\section{RESULTADOS E DISCUSSÃO}

A massa de líquido drenado foi afetada de modo significativo pela interação entre modificação atmosférica e tempo de armazenamento $(\mathrm{p}<0,05)$ (Tabela 1$)$.

Notou-se um aumento na quantidade de líquido drenado no transcorrer do armazenamento, a despeito dos tratamentos utilizados. As diferenças estatísticas observadas não sugerem efeitos marcantes dos diferentes tratamentos sobre a variável estudada. Do ponto de vista prático, as perdas foram insignificantes, não atingindo 0,01\% (Tabela 1). Sarzi (2002), trabalhando com abacaxis desta mesma cultivar minimamente processados, verificou que os frutos perderam suco durante o armazenamento, principalmente quando estes foram submetidos à temperaturas mais altas $\left(9^{\circ} \mathrm{C}\right)$, e foi possível observar também que o tipo de corte influenciou a quantidade de líquido drenado, ou seja, quanto maior a intensidade dos cortes, maior a perda durante o armazenamento. 
TABELA 1 - Valores médios de líquido drenado, açúcares solúveis totais e acidez total titulável de abacaxi 'Pérola' minimamente processado, armazenado a $5 \pm 1^{\circ} \mathrm{C}$ e $85 \%$ de UR, em função de diferentes atmosferas modificadas (AMP: atmosfera modificada passiva, AM1: atmosfera modificada com $5 \% \mathrm{O}_{2}+5 \% \mathrm{CO}_{2}$, AM2: atmosfera modificada com $2 \% \mathrm{O}_{2}+10 \% \mathrm{O}_{2}$ ) e em função do tempo de armazenamento.

\begin{tabular}{ccccccc}
\hline \multirow{2}{*}{ Tratamentos } & \multicolumn{7}{c}{ Armazenamento (dias) } \\
\cline { 2 - 6 } & 0 & 2 & 4 & 6 & 8 & 10 \\
\hline \multicolumn{7}{c}{ Líquido drenado (mg/100g) } \\
\hline AMP & --- & $4,0 \mathrm{a}$ & $5,6 \mathrm{a}$ & $5,9 \mathrm{~b}$ & $6,9 \mathrm{~b}$ & $8,1 \mathrm{~b}$ \\
AM 1 & --- & $3,6 \mathrm{a}$ & $5,2 \mathrm{ab}$ & $7,3 \mathrm{a}$ & $8,3 \mathrm{a}$ & $8,5 \mathrm{a}$ \\
AM 2 & --- & $3,5 \mathrm{a}$ & $4,9 \mathrm{~b}$ & $5,9 \mathrm{~b}$ & $6,5 \mathrm{~b}$ & $8,3 \mathrm{ab}$ \\
\hline \multicolumn{7}{c}{ Açúcares solúveis totais (\%) } \\
\hline AMP & $12,8 \mathrm{a}$ & $11,7 \mathrm{~b}$ & $12,0 \mathrm{~b}$ & $12,0 \mathrm{~b}$ & $12,5 \mathrm{a}$ & $12,2 \mathrm{~b}$ \\
AM 1 & $13,3 \mathrm{a}$ & $13,3 \mathrm{a}$ & $12,7 \mathrm{~b}$ & $13,2 \mathrm{a}$ & $13,6 \mathrm{a}$ & $12,7 \mathrm{ab}$ \\
AM 2 & $13,0 \mathrm{a}$ & $13,8 \mathrm{a}$ & $15,2 \mathrm{a}$ & $13,2 \mathrm{a}$ & $12,5 \mathrm{a}$ & $13,8 \mathrm{a}$ \\
\hline \multicolumn{7}{c}{ Acidez total titulável (\%) } \\
\hline AMP & $0,53 \mathrm{a}$ & $0,55^{\mathrm{a}}$ & $0,63 \mathrm{a}$ & $0,59 \mathrm{a}$ & $0,57 \mathrm{~b}$ & $0,64 \mathrm{a}$ \\
AM 1 & $0,53 \mathrm{a}$ & $0,54^{\mathrm{a}}$ & $0,56 \mathrm{~b}$ & $0,57 \mathrm{a}$ & $0,66 \mathrm{a}$ & $0,55 \mathrm{~b}$ \\
AM 2 & $0,53 \mathrm{a}$ & $0,57^{\mathrm{a}}$ & $0,60 \mathrm{ab}$ & $0,59^{\mathrm{a}}$ & $0,61 \mathrm{ab}$ & $0,57 \mathrm{~b}$ \\
\hline
\end{tabular}

Médias seguidas da mesma letra, na coluna, são iguais entre si pelo teste de Tukey (5\%).

A firmeza dos leques de abacaxi foi influenciada pela atmosfera modificada, isoladamente, enquanto efeito interativo foi observado quanto às variáveis pectina solúvel e poligalacturonase. A atmosfera $2 \% \mathrm{O}_{2}+10 \%$ $\mathrm{CO}_{2}$ determinou, em média, maior firmeza nos leques (Tabela 2) e menor solubilização péctica aos 6 e 10 dias de armazenamento, enquanto a atmosfera 5\% $\mathrm{O}_{2}+5 \%$ $\mathrm{CO}_{2}$ menor solubilização péctica, a partir do quarto dia de armazenamento, em comparação com o controle (Tabela 3). Uma das mais flagrantes modificações observadas durante o armazenamento de frutos "in natura" e minimamente processados é o amaciamento. O amaciamento observado ao longo do armazenamento de frutos é, normalmente, relacionado à degradação de pectinas, associada à ação das enzimas pectinametilesterase e poligalacturonase.

Atividade da enzima PME não foi detectada nos frutos estudados. Não obstante, os leques sob atmosfera modificada ativa, a despeito da concentração de gases, apresentaram menor atividade da enzima PG até o sexto dia de armazenamento (Tabela 3). Menor atividade de PG ainda foi detectada nos frutos sob a atmosfera 5\%
$\mathrm{O}_{2}+5 \% \mathrm{CO}_{2}$ no oitavo dia de armazenamento. Huet (1958) relata que a PME exibe uma fraca atividade no abacaxi e Guerra (1979) evidencia que, nos estádios mais avançados de desenvolvimento do fruto, essa enzima não exibe qualquer atividade. A menor solubilização péctica, nos frutos sob atmosfera modificada ativa, pode ser relacionada à menor atividade da PG, a principal enzima responsável pela degradação, refletindo-se em frutos mais firmes.

Observou-se efeito significativo dos tratamentos (modificação atmosférica) sobre a variável SST (Tabela 2). Abacaxis armazenados sob atmosfera modificada $5 \% \mathrm{O}_{2}+5 \% \mathrm{CO}_{2}$ apresentaram teor médio de SST superior aos frutos controle, embora semelhante aos abacaxis sob $2 \% \mathrm{O}_{2}+10 \% \mathrm{CO}_{2}$, o que sugere um benéfico efeito da atmosfera modificada ativa sobre a manutenção da doçura original do produto. Neste estudo encontrou-se uma média de SST de $14,2{ }^{\circ}$ Brix, valor semelhante aos observados por Silva et al. (2003) ao trabalharem com abacaxi 'Pérola' minimamente processado, em torno de $13,5^{\circ}$ Brix. 
Avaliação da qualidade do abacaxi "Pérola” minimamente processado...

TABELA 2 - Valores médios de firmeza, sólidos solúveis totais (SST), pH e vitamina C de abacaxis 'Pérola' minimamente processados, armazenados a $5 \pm 1^{\circ} \mathrm{C}$ e $85 \%$ de UR, em função de diferentes atmosferas modificadas (AMP: atmosfera modificada passiva, AM1: atmosfera modificada com $5 \% \mathrm{O}_{2}+5 \% \mathrm{CO}_{2}$, AM2: atmosfera modificada com $2 \% \mathrm{O}_{2}+10 \% \mathrm{CO}_{2}$ ) e em função do tempo de armazenamento.

\begin{tabular}{ccccc}
\hline \multirow{2}{*}{ Tratamentos } & \multicolumn{3}{c}{ Variáveis } \\
\cline { 2 - 5 } & Firmeza (N) & SST $\left({ }^{\circ}\right.$ Brix) & pH & Vit. C (mg/100g) \\
\hline AMP & $0,26 \mathrm{~b}$ & $13,9 \mathrm{~b}$ & $3,6^{\mathrm{a}}$ & $31,7 \mathrm{a}$ \\
AM 1 & $0,27 \mathrm{ab}$ & $14,5 \mathrm{a}$ & $3,6^{\mathrm{a}}$ & $31,4 \mathrm{a}$ \\
AM 2 & $0,28 \mathrm{a}$ & $14,3 \mathrm{ab}$ & $3,6^{\mathrm{a}}$ & $30,9 \mathrm{a}$ \\
\hline
\end{tabular}

Médias seguidas da mesma letra, na coluna, são iguais entre si pelo teste de Tukey (5\%).

TABELA 3 - Valores médios de pectina solúvel (PS) e atividade de poligalacturonase (PG) de abacaxi 'Pérola' minimamente processado, armazenado a $5 \pm 1^{\circ} \mathrm{C}$ e $85 \%$ de UR, em função de diferentes atmosferas modificadas (AMP: atmosfera modificada passiva, AM1: atmosfera modificada com 5\% $\mathrm{O}_{2}+5 \% \mathrm{CO}_{2}$, AM2: atmosfera modificada com $2 \% \mathrm{O}_{2}+10 \% \mathrm{O}_{2}$ ) e em função do tempo de armazenamento.

\begin{tabular}{ccccccc}
\hline Tratamentos & \multicolumn{7}{c}{ Armazenamento (dias) } \\
\cline { 2 - 7 } & $\mathbf{0}$ & $\mathbf{2}$ & $\mathbf{4}$ & $\mathbf{6}$ & $\mathbf{8}$ & $\mathbf{1 0}$ \\
\hline \multirow{2}{*}{ PS (mg ácido galacturônico/100g) } \\
AMP & $12,9 \mathrm{a}$ & $14,7 \mathrm{a}$ & $17,0 \mathrm{a}$ & $19,4 \mathrm{a}$ & $19,3 \mathrm{a}$ & $26,7 \mathrm{a}$ \\
AM 1 & $12,6 \mathrm{a}$ & $14,5 \mathrm{a}$ & $15,8 \mathrm{ab}$ & $17,1 \mathrm{~b}$ & $18,8 \mathrm{a}$ & $21,9 \mathrm{~b}$ \\
AM 2 & $13,3 \mathrm{a}$ & $13,9 \mathrm{a}$ & $14,2 \mathrm{~b}$ & $15,5 \mathrm{~b}$ & $16,2 \mathrm{~b}$ & $17,3 \mathrm{c}$ \\
& & & PG (U/min/g) & & \\
AMP & $47,3 \mathrm{a}$ & $64,5 \mathrm{a}$ & $69,8 \mathrm{a}$ & $66,9 \mathrm{a}$ & $63,4 \mathrm{a}$ & $53,1 \mathrm{a}$ \\
AM 1 & $32,8 \mathrm{~b}$ & $42,0 \mathrm{~b}$ & $42,3 \mathrm{~b}$ & $42,7 \mathrm{~b}$ & $37,4 \mathrm{~b}$ & $48,5 \mathrm{a}$ \\
AM 2 & $36,0 \mathrm{~b}$ & $36,1 \mathrm{~b}$ & $30,6 \mathrm{c}$ & $52,1 \mathrm{~b}$ & $60,8 \mathrm{a}$ & $46,4 \mathrm{a}$ \\
\hline
\end{tabular}

Médias seguidas da mesma letra, na coluna, são iguais entre si pelo teste de Tukey (5\%).

Açúcares solúveis totais (AST) são carboidratos de baixo peso molecular, componentes dos SST, responsáveis diretos pela determinação do sabor doce dos frutos. Observou-se oscilação nos teores de AST durante o armazenamento dos abacaxis minimamente processados. A análise estatística detectou efeito significativo da interação entre atmosfera modificada e tempo de armazenamento, em relação aos AST. Verificou-se que o tratamento com $2 \% \mathrm{O}_{2}+10 \% \mathrm{CO}_{2}$ determinou, em geral, maiores teores de açúcares solúveis totais em relação ao controle ao longo do armazenamento, embora não tenha diferido do tratamento $5 \% \mathrm{O}_{2}+5 \% \mathrm{CO}_{2}$, a exceção do quarto dia de armazenamento (Tabela 1). Os menores valores foram encontrados nos frutos sob atmosfera modificada passiva (controle), com exceção dos tempos 0 e 8 dias nos quais não foi detectada diferença significativa entre os tratamentos. Sugere-se novamente, um efeito positivo da atmosfera modificada ativa, comparada à passiva, sobre a preservação da doçura do abacaxi 'Pérola' minimamente processado. Sarzi (2002), ao trabalhar com o abacaxi 'Pérola' minimamente processado encontrou uma média de $12,66 \% \pm 2,22 \%$ de AST, concordando com os valores obtidos neste trabalho. 
$\mathrm{O}$ pH não foi influenciado pelos fatores isoladamente, tampouco pela interação entre eles, enquanto a acidez total titulável foi afetada pela interação atmosfera modificada e tempo de armazenamento (Tabelas 1 e 2). No presente estudo, encontrou-se um $\mathrm{pH}$ médio de 3,6 (Tabela 2) situado dentro da amplitude de 3,4 a 3,8 apresentada por Silva et al. (2003), ao trabalharem com abacaxi 'Pérola' minimamente processado. A ATT dos frutos controle não diferiu daquela obtida nos frutos sob $2 \% \mathrm{O}_{2}+10 \% \mathrm{CO}_{2}$, a exceção do décimo dia de armazenamento, quando a ATT dos frutos controle foi superior (Tabela1). Comparado aos frutos sob $5 \% \mathrm{O}_{2}+5 \%$ $\mathrm{CO}_{2}$, observou-se maior ATT nos frutos controle aos 4 e 10 dias, embora a ATT dos frutos controle tenha sido inferior aos 8 dias de armazenamento. Os abacaxis minimamente processados sob as duas atmosferas modificadas ativas não diferiram entre si ao longo do armazenamento, com relação a esta variável. Uma pequena oscilação na ATT, durante o armazenamento de abacaxis 'Pérola' "in natura" e minimamente processados foi observada por Vilas Boas \& Lima (1999) e por Sarzi (2002), respectivamente. Logo, os resultados obtidos não sugerem efeitos distintos das atmosferas modificadas sobre o $\mathrm{pH}$ e acidez total titulável dos frutos.

Não foi observado efeito significativo entre tratamento e tempo de armazenamento ou tratamento isoladamente, para o teor de vitamina C (Tabela 2). Neste estudo, foi encontrado um teor médio de Vitamina C de $31,7 \mathrm{mg}$ de ácido ascórbico.100 g ${ }^{-1}$. Sarzi et al. (2002) ao trabalharem com o fruto minimamente processado da mesma variedade, encontraram uma amplitude de 24-27 mg.100 g $\mathrm{g}^{-1}$, valores menores do que os encontrados no trabalho em questão. $\mathrm{O}$ ácido ascórbico é altamente sensível a condições adversas de temperatura, luz, oxigênio e $\mathrm{pH}$ se oxidando rapidamente a produtos sem a atividade biológica de vitamina $\mathrm{C}$, sendo considerado um bom indicador da qualidade de frutas e hortaliças.

A análise sensorial dos frutos determinou a superioridade da atmosfera modificada passiva sobre as atmosferas modificadas ativas, do ponto de vista da aparência e cor, a partir dos dois dias de armazenamento (Tabela 4). Quanto ao sabor, nenhuma diferença foi detectada entre os tratamentos até o quarto dia de armazenamento, sendo que os frutos sob atmosfera modificada passiva foram superiores aos sob atmosfera modificada $5 \% \mathrm{O}_{2}+5 \% \mathrm{CO}_{2}$, aos 6 dias de armazenamento e aos sob ambas atmosferas modificadas ativas, aos 8 dias de armazenamento (Tabela 4). Considerando-se 5 como a nota mínima para os frutos serem considerados aptos para o consumo, a vida útil do abacaxi 'Pérola' minimamente processado foi de 4 dias, quando submetido à atmosfera $5 \% \mathrm{O}_{2}+5 \% \mathrm{CO}_{2}$ e 8 dias quando submetido à atmosfera $2 \% \mathrm{O}_{2}+10 \% \mathrm{CO}_{2}$ e passiva. A exposição de frutas e hortaliças a baixas concentrações de $\mathrm{O}_{2}$ e altas de $\mathrm{CO}_{2}$ pode levá-las à respiração anaeróbica e injúrias fisiológicas que culminam com alterações indesejáveis na coloração, aroma e gosto (VILAS BOAS, 1999). Logo, a atmosfera de equilíbrio nas embalagens contendo os frutos sob as atmosferas modificadas ativas pode ter sido injuriosa e detrimental, comparada à atmosfera de equilíbrio dos frutos sob atmosfera modificada passiva.

TABELA 4 - Valores médios de aparência, cor e sabor (notas) de abacaxi 'Pérola' minimamente processado, armazenado a $5 \pm 1^{\circ} \mathrm{C}$ e $85 \%$ de UR, em função de diferentes atmosferas modificadas (AMP: atmosfera modificada passiva, AM1: atmosfera modificada com $5 \% \mathrm{O}_{2}+5 \% \mathrm{CO}_{2}$, AM2: atmosfera modificada com $2 \% \mathrm{O}_{2}+10 \% \mathrm{CO}_{2}$ ) e em função do tempo de armazenamento.

\begin{tabular}{cccccc}
\hline \multirow{2}{*}{ Tratamentos } & \multicolumn{5}{c}{ Armazenamento (dias) } \\
\cline { 2 - 6 } & $\mathbf{0}$ & $\mathbf{2}$ & $\mathbf{4}$ & $\mathbf{6}$ & $\mathbf{8}$ \\
\hline \multicolumn{7}{c}{ Aparência e cor } \\
\hline AMP & $6,7 \mathrm{a}$ & $6,2 \mathrm{a}$ & $6,4 \mathrm{a}$ & $6,2 \mathrm{a}$ & $6,2 \mathrm{a}$ \\
AM 1 & $7,0 \mathrm{a}$ & $5,0 \mathrm{~b}$ & $5,1 \mathrm{~b}$ & $3,8 \mathrm{c}$ & $2,8 \mathrm{c}$ \\
AM 2 & $6,8 \mathrm{a}$ & $5,3 \mathrm{~b}$ & $5,4 \mathrm{~b}$ & $5,3 \mathrm{~b}$ & $5,4 \mathrm{~b}$ \\
\hline & & \multicolumn{7}{c}{ Sabor } \\
\hline AMP & $7,3 \mathrm{a}$ & $7,3 \mathrm{a}$ & $6,9 \mathrm{a}$ & $7,1 \mathrm{a}$ & $7,1 \mathrm{a}$ \\
AM 1 & $6,8 \mathrm{a}$ & $6,8 \mathrm{a}$ & $6,4 \mathrm{a}$ & $5,1 \mathrm{~b}$ & $3,7 \mathrm{~b}$ \\
AM 2 & $6,9 \mathrm{a}$ & $6,8 \mathrm{a}$ & $6,9 \mathrm{a}$ & $6,3 \mathrm{a}$ & $5,8 \mathrm{c}$ \\
\hline
\end{tabular}

Médias seguidas da mesma letra, na coluna, são iguais entre si pelo teste de Tukey (5\%). 
As análises microbiológicas das amostras analisadas apresentaram baixas contagens microbiológicas dos microrganismos dos grupos de coliformes a $35^{\circ} \mathrm{C}$ (totais) e $45^{\circ} \mathrm{C}$ (fecais) e também de fungos filamentosos e leveduras (Tabela 5). Os baixos números de fungos filamentosos, leveduras e coliformes encontrados inicialmente refletem as boas práticas de fabricação. O’Connor-Shaw et al. (1994), quando trabalharam com esse mesmo fruto armazenado à $4^{\circ} \mathrm{C}$ durante 11 dias, encontraram valores próximos em relação a fungos filamentosos e leveduras, e relatam ainda que este cres- cimento microbiano em princípio não contribuiu para a deterioração do abacaxi.

Ainda não existe legislação com limites de contagens microbiológicas toleradas, para frutos e hortaliças minimamente processados. Assim, utiliza-se a legislação para frutas frescas, inteiras refrigeradas ou congeladas, consumidas diretamente, que estipula somente o limite para coliformes fecais, o qual é de $2 \times 10^{2} / \mathrm{g}$. Para os demais grupos microbianos, não existe legislação pertinente. Portanto, os resultados microbiológicos obtidos sugerem um produto seguro para o consumidor.

TABELA 5 - Valores médios de coliformes a $35^{\circ} \mathrm{C}$ e $45^{\circ} \mathrm{C}$ e de fungos filamentosos e leveduras de abacaxi 'Pérola' minimamente processado, armazenado a $5 \pm 1^{\circ} \mathrm{C}$ e $85 \%$ de UR, em função de diferentes atmosferas modificadas (AMP: atmosfera modificada passiva, AM1: atmosfera modificada com 5\% $\mathrm{O}_{2}+5 \% \mathrm{CO}_{2}$, AM2: atmosfera modificada com $2 \% \mathrm{O}_{2}+10 \% \mathrm{CO}_{2}$ ) e em função do tempo de armazenamento.

\begin{tabular}{|c|c|c|c|c|c|c|}
\hline \multirow[t]{2}{*}{ Tratamentos } & \multicolumn{6}{|c|}{ Armazenamento (dias) } \\
\hline & $\mathbf{0}$ & 2 & 4 & 6 & 8 & 10 \\
\hline \multicolumn{7}{|c|}{ Coliformes a $35^{\circ} \mathrm{C}$ (NMP/g) } \\
\hline AMP & $5,3 \times 10^{1}$ & $59,0 \times 10^{1}$ & $15,7 \times 10^{1}$ & $1,0 \times 10^{1}$ & $<0,3$ & $<0,3$ \\
\hline AM 1 & $0,6 \times 10^{1}$ & $39,5 \times 10^{1}$ & $2 \times 10^{1}$ & $0,4 \times 10^{1}$ & $<0,3$ & $<0,3$ \\
\hline AM 2 & $1,7 \times 10^{1}$ & $10,2 \times 10^{1}$ & $1,3 \times 10^{1}$ & $0,5 \times 10^{1}$ & $0,4 \times 10^{1}$ & $<0,3$ \\
\hline \multicolumn{7}{|c|}{ Coliformes a $45^{\circ} \mathrm{C}(\mathrm{NMP} / \mathrm{g})$} \\
\hline AMP & $<0,3$ & $<0,3$ & $<0,3$ & $<0,3$ & $<0,3$ & $<0,3$ \\
\hline AM 1 & $<0,3$ & $<0,3$ & $<0,3$ & $<0,3$ & $<0,3$ & $<0,3$ \\
\hline AM 2 & $<0,3$ & $<0,3$ & $<0,3$ & $<0,3$ & $<0,3$ & $<0,3$ \\
\hline \multicolumn{7}{|c|}{ Fungos filamentosos e leveduras (UFC/g) } \\
\hline AMP & $5,0 \times 10^{3}$ & $8,1 \times 10^{4}$ & $2,9 \times 10^{6}$ & $3,6 \times 10^{5}$ & $3,1 \times 10^{3}$ & $7,1 \times 10^{4}$ \\
\hline AM 1 & $4,3 \times 10^{3}$ & $4,3 \times 10^{5}$ & $1,7 \times 10^{8}$ & $4,1 \times 10^{4}$ & $5,0 \times 10^{3}$ & $3,7 \times 10^{4}$ \\
\hline AM 2 & $2,1 \times 10^{3}$ & $3,2 \times 10^{6}$ & $4,3 \times 10^{8}$ & $7,3 \times 10^{3}$ & $3,8 \times 10^{4}$ & $5,8 \times 10^{4}$ \\
\hline
\end{tabular}




\section{CONCLUSÕES}

A atmosfera modificada ativa diminui a atividade da enzima poligalacturonase, reduz a solubilização péctica e previne o amaciamento de abacaxi 'Pérola' minimamente processado.

A atmosfera modificada ativa, comparada à passiva, não afeta as variáveis $\mathrm{pH}$ e vitamina $\mathrm{C}$ total, embora na concentração inicial de $2 \% \mathrm{O}_{2}+10 \% \mathrm{CO}_{2}$ proporcione maiores valores de sólidos solúveis totais no abacaxi 'Pérola' minimamente processado.

Boas práticas de fabricação, embalagem e o respeito à cadeia de frio permitem a obtenção e manutenção do abacaxi minimamente processado seguro microbiologicamente por 10 dias.

A vida útil de abacaxi 'Pérola' minimamente processado é de 4 dias, para aqueles armazenados sob atmosfera modificada ativa de $5 \% \mathrm{O}_{2}+5 \% \mathrm{CO}_{2}$ e 8 dias para aqueles armazenados sob a atmosfera modificada ativa de $2 \% \mathrm{O}_{2}+10 \% \mathrm{CO}_{2}$ e passiva, à $5 \pm 1^{\circ} \mathrm{C}$, de acordo com análise sensorial.

A qualidade sensorial de abacaxi 'Pérola' minimamente processado armazenado a $5 \pm 1^{\circ} \mathrm{C}$, por 8 dias, sob atmosfera modifica passiva é superior a daquele armazenado sob atmosfera modificada ativa.

\section{AGRADECIMENTOS}

Os autores agradecem a CAPES pela concessão da bolsa de estudos ao primeiro autor.

\section{REFERÊNCIAS BIBLIOGRÁFICAS}

ASSOCIATION OF OFFICIAL ANALYTICAL CHEMISTRY. Official methods of analysis of the Association of Official Analytical Chemistry. 12. ed. Washington, 1992.

BLUMENKRANTZ, N.; ASBOE-HANSEN, G. New method for quantitative determination of uronic acids. Analytical Biochemistry, New York, v. 54, p. 484489, 1973.

BONNAS, D. S. et al. Qualidade do abacaxi 'Smooth cayenne' minimamente processado. Revista Brasileira de Fruticultura, Cruz das Almas, v. 25, n. 2, p. 206-209, 2003.

BRACKETT, R. E. Shelf stability and safety of fresh produce as influenced by sanitation and disinfection. Journal of Food Protection, Ames, v. 55, n. 10, p. 808-814, 1992.
BUESCHER, R. W.; FURMANSKI, R. J. Role of pectinesterase and polygalacturonase in the formation of woolliness in peaches. Journal of Food Science, Chicago, v. 43, n. 1, p. 264-266, Jan./Feb. 1978.

DAREZZO, H. M. Processamento mínimo de alface (Lactuca sativa L.). In: ENCONTRO NACIONAL SOBRE PROCESSAMENTO MÍNIMO DE FRUTAS E HORTALIÇAS, 2., 2000, Viçosa. Palestras... Viçosa: UFV, 2000. p. 117-124.

DISCHE, E. Color reactions of carbohydrates. In: WHISTLER, R. L.; WOLFRAM, M. L. (Eds.). Methods in carbohydrates chemistry. New york: Academic, 1962. v. 1, p. 477-512.

FANTUZZI, E. Atividade microbiana em repolho (Brassica oleraceae cv. apitata) minimamente processado. 1999. 50 f. Dissertação (Mestrado em Microbiologia Agrícola) - Universidade Federal de Viçosa, Viçosa, 1999.

FERREIRA, D. F. Análises estatísticas por meio do SISVAR para windows versão 4.0. In: REUNIÃO ANUAL DA REGIÃO BRASILEIRA DA SOCIEDADE INTERNACIONAL DE BIOMETRIA, 45., 2000, São Carlos. Resumos... São Carlos: UFSCar, 2000. p. 235.

GUERRA, N. B. Abacaxi no nordeste: desenvolvimento, maturidade para a colheita e fisiologia póscolheita. 1979. 105 f. Tese (Doutorado em Ciências dos Alimentos) - Universidade de São Paulo, São Paulo, 1979.

HUET, R. La composition chimique de l'ananas. Fruits, Paris, v. 13, n. 5, p. 183-197, mayo 1958.

HULTIN, H. O.; SUN, B.; BULGER, J. Pectin methyl esterases of the banana: purification and properties. Journal of Food Science, Chicago, v. 31, n. 3, p. 320327, May/June 1966.

INTERNATIONAL Fresh-cut Produce Association. 2002. Disponível em: <http://www.fresh-cuts.org>. Acesso em: 25 fev. 2003.

MARKOVIC, O.; HEINRICHOVÁ, K.; LENKEY, B. Pectolytic enzymes from banana. Collection Czechoslovak Chemistry Community, London, v. 40, p. 769-774, 1975. 
MARRERO, A.; KADER, A. A. Factors affecting the post-cutting life and quality of minimally processed pineapple. Acta Horticulture, The Hague, v. 553, p. 705-706, 2001. Disponível em: <http://www.actahort.org/books/553/553_175.htm>. Acesso em: 20 fev. 2003.

MARTENS, M.; BAARSETH, P. Postharvest quality changes, sensory quality. In: WEICHMANN, J. Postharvest physiology of vegetables. New York: Dekker, 1987. p. 597.

McCREADY, R. M.; McCOMB, E. A. Extraction and determination of total pectic materials in fruit. Analytical Chemistry, Washington, v. 24, n. 12, p. 1586-1588, Dec. 1952. (Série frutas tropicais).

O'CONNOR-SHAW, R. E. et al. Shelf life of minimally processed honeydew, kiwifruit, papaya, pineapple and cantaloupe. Journal of Food Science, Chicago, v. 59, n. 6, p. 1202-1215, 1994.

PIROVANI, M. E. et al. Quality of minimally processed lettuce as influenced by packaging and chemical treatment. Journal of Food Quality, Wastport, v. 22, p. 475-484, 1998.

RATNER, A.; GOREN, R.; MONSELINE, S. P. Activity of pectin esterase and cellulase in the abcission zone of citrus leaf explants. Plant Physiology, Washington, v. 44, n. 12, p. 1717-1723, Dec. 1969.

SARZI, B. Conservação de abacaxi e mamão minimamente processados: associação entre o preparo, a embalagem e a temperatura de armazenamento. 2002. 100 f. Dissertação (Mestrado em Produção Vegetal) - Faculdade de Ciências Agrárias e Veterinárias, Universidade Estadual Paulista, Jaboticabal, 2002.
SILVA, G. C. et al. Efeito de diferentes concentrações de cloreto de cálcio na qualidade do abacaxi 'Pérola' minimamente processado. Revista Brasileira de Fruticultura, Cruz das Almas, v. 25, n. 2, p. 216-219, 2003.

STROHECKER, R. L.; HENNING, H. M. Analisis de vitaminas: métodos comprobados. Madrid: Paz Montalvo, 1967. 428 p.

VANDERZANT, C.; SPLITTSTOESSSER, D. F. Compendium of methods for the microbiological examination of foods. 3. ed. Washington: APHA, 1962.

VILAS BOAS, E. V. de B. Aspectos fisiológicos do desenvolvimento de frutos. Lavras: UFLA/FAEPE/DCA, 1999. 75 p.

VILAS BOAS, E. V. de B. Modificações pós-colheita de banana 'Prata' (Musa acuminata x Musa balbisiana grupo AAB) $\gamma$-irradiada. 1995. 73 f. Dissertação (Mestrado em Ciência dos Alimentos) - Universidade Federal de Lavras, Lavras, 1995.

VILAS BOAS, E. V. de B. Tecnologia de processamento mínimo de banana, mamão e kiwi. In: SEMINÁRIO INTERNACIONAL DE PÓS-COLHEITA E PROCESSAMENTO MÍNIMO DE FRUTAS E HORTALIÇAS, 2002, Brasília, DF. Anais... Brasília: EMBRAPA, 2002. p. 1-7.

VILAS BOAS, E. V. de B.; KADER, A. A. Effect of 1-MCP on fresh-cut fruits. Perishables Handling Quarterly, [S.l.], n. 108, p.25-25, 2001.

VILAS BOAS, E. V. de B.; LIMA, L. C. de O. Armazenamento de abacaxi pérola. In: SIMPÓSIO LATINO AMERICANO DE CIÊNCIA DE ALIMENTOS, 3., 1999, Campinas. Anais... Campinas: UNICAMP, 1999. p. 45. 